\title{
Separation of volatile compounds from fermentation broth by membrane distillation
}

\author{
Marek Gryta, Marta Barancewicz \\ West Pomeranian University of Technology, Szczecin, Institute of Chemical Technology and Environment Engineering, \\ ul. Pułaskiego 10, 70-322 Szczecin, Poland
}

\begin{abstract}
The diluted ethanol solutions and fermentation broth (Saccharomyces cerevisiae) were separated by membrane distillation (MD). Hydrophobic macroporous (pore size $0.2 \mu \mathrm{m}$ ) capillary polypropylene membranes, Accurel PP V8/2 HF and Accurel PP S6/2, were used for these studies. The MD process can be successfully applied to remove the volatile components from the fermentation broth. Besides ethanol, propionic and acetic acids were moved from the broth to the distillate. Therefore, the course of the fermentation carried out in a membrane distillation bioreactor considerably accelerate its rate and increase the efficiency by a selective removal of fermentation products. It was found that the broth subjected to the separation did not affect the hydrophobic properties of the polypropylene membrane assembled in the MD modules.
\end{abstract}

Keywords: fermentation, ethanol, membrane distillation.

\section{INTRODUCTION}

The ethanol production from biomass is one of many options available for obtaining oil substitutes. However, the conventional process of ethanol generation using batch fermentation of sugars with yeast, followed by distillation to recover ethanol is uneconomical compared to fossil fuels ${ }^{\mathbf{1}, \mathbf{2}}$. Climatic conditions have a considerable impact on the effectiveness of ethanol production. In northern Europe, due to a long period of vegetation, the traditional crops such as wheat and potatoes are expensive and they constitute more than $50 \%$ of the cost of ethanol production $^{3}$. In the tropics, on the other hand, it is possible to grow two or three crops a year, and sugar cane grown for ethanol in e.g. Brazil, is financially ${ }^{1}$. Cost saving in the ethanol production can be achieved by using plant materials, which are less expensive. Much work has focused on the conversion of cellulose to ethanol. However, the efficiency is still too low for this to be a realistic process ${ }^{1-4}$. Therefore, additional research and development are needed in order to reduce the cost of ethanol production.

The energy cost is the second largest factor in ethanol production after the cost of the raw material consumption. The majority of energy is used for broth distillation which contains only 5-12\% ethanol after completing the sugar fermentation process ${ }^{2,5}$. An increase in the ethanol concentration would lower the cost of distillation but it is difficult to obtain higher concentrations in the classic feed-batch fermentation due to inhibition phenomena ${ }^{2-6}$. Another serious problem is the significant amount of wastewater discharged from the distillation column (stillage). Wastewater poses a threat to the environment and must be managed, which leads to a significant increase in the energy consumption during the process.

One method to manage stillage is concentration through evaporation and then drying in order to obtain a protein additive for animal feeding. The condensates produced from stillage evaporation process constitute low-polluted water, and can be recycled as dilution water for the fermentation step. The recycling or reuse of low-polluted wastewater after adequate purification treatment may help to limit its environmental impact. The major drawback is the presence of compounds which inhibit fermentation such as: aliphatic acids (formic, acetic, propionic, butyric, valeric and hexanoic), alcohols (2,3-butanediol), aromatic compounds (phenyl-2-ethyl-alcohol) and furane derivatives (furfural) ${ }^{6}$. A substantial part of these compounds can be removed using the treatment of condensate by reverse osmosis ${ }^{6,7}$. However, such solutions inevitably increase the cost of alcohol production.

The fermentation problems can be solved to a considerable degree by decreasing the amount of stillage, which can be achieved by using the membrane bioreactors for ethanol production $^{8,9}$. The membrane separation retains yeast cells in the bioreactor, which facilitates the ethanol distillation from the obtained filtrate. A continuous dosing of the substrates and an increase of yeast concentration in the broth improves the productivity and efficiency of the bioreactor. Microfiltration (MF) is usually used as the separation method, although it does not reduce the amount of effluents produced during ethanol distillation. However, a clear solution of ethanol devoid of any microorganisms is obtained after the MF process, and the expensive process of stillage evaporation is no longer necessary. After the removal of organic acids e.g. by reverse osmosis ${ }^{6}$, such solution can be reused as technological water in the fermentation process.

The amount of waste generated in the process will be considerably reduced provided that produced ethanol will be separated from the bioreactor, whereas the remaining constituents of the broth will remain in the bioreactor. This, however, requires the application of a process enabling a selective separation of ethanol. Vacuum fermentation, extractive fermentation and membrane processes, such as pervaporation and membrane distillation (MD), can be proposed for this purpose $\mathrm{e}^{\mathbf{1 0 - 1 5}}$.

MD is the evaporation of volatile feed components through air-filled pores of a hydrophobic membrane. The composition of the permeate diffusing through the membrane pores depends on the partial pressure of respective components of the feed. At a given temperature, the volatility of ethanol is higher, causing the obtained permeate to be enriched in ethanol ${ }^{14}$.

The use of MD for removal of ethanol and other volatile metabolites from broth will both decrease the inhibitory 
effect of these compounds on microbial culture and reduce the cost of further concentration of alcohol. The main advantage of $\mathrm{MD}$ over conventional distillation processes is that membrane distillation takes place at a temperature below the normal boiling point of broth solutions. However, the major requirement of MD process is that the used membranes must not be wetted by separated solutions. To avoid membrane wettability, highly hydrophobic membranes with an appropriate pore size (below $1 \mu \mathrm{m}$ ) should be used $^{16}$.

The separation mechanism in MD is based first on the difference in volatility, and second, on the difference in diffusion rates among the transferring species ${ }^{\mathbf{1 3 , 1 4}}$. For this reason, it is possible to increase the degree of separation by increasing the length of the diffusion pathway (diffusion distillation ${ }^{17}$ ). Moreover, one can expect the differences in the values of enrichment coefficient for membranes with differing wall thickness.

In the present study, two kinds of polypropylene capillary membranes were used, differing in the wall thickness more than three times, to separate the ethanol solutions by MD process. MD was also used to separate the volatile compounds produced in the bioreactor during the fermentation of sucrose solutions with the participation of the yeast species Saccharomyces cerevisiae.

\section{EXPERIMENTAL}

The design of membrane bioreactor can be simplified by placing of the membranes directly in the reactor tank. This variant was tested in this work using the installation that is schematically presented in Fig. 1. Two membrane modules made of polypropylene capillary membranes, Accurel PP S6/2 and Accurel PP V8/2 HF (Membrana $\mathrm{GmbH}$, Germany), were placed inside a glass reactor (6 $\left.\mathrm{dm}^{3}\right)$. The applied membranes had pore sizes with the nominal diameter of $0.2 \mu \mathrm{m}$, and the porosity of $73 \%$ (the manufacturer's data). The outside/inside diameter of S6/2 and $\mathrm{V} 8 / 2 \mathrm{HF}$ was equal to $2.6 / 1.8 \mathrm{~mm}$ and $8.6 / 5.5 \mathrm{~mm}$, respectively. In the module MK1 one membrane V8/2 HF was assembled with a length of $11.5 \mathrm{~cm}\left(\mathrm{~F}_{1}=31 \mathrm{~cm}^{2}\right)$, whereas the module MK2 was made of three membranes $\mathrm{S} 6 / 2$ with a length of $17 \mathrm{~cm}$ each $\left(\mathrm{F}_{2}=41.6 \mathrm{~cm}^{2}\right)$.

The bioreactor tank was placed on a magnetic stirrer RCT B (IKA, Germany) with automatic temperature con-

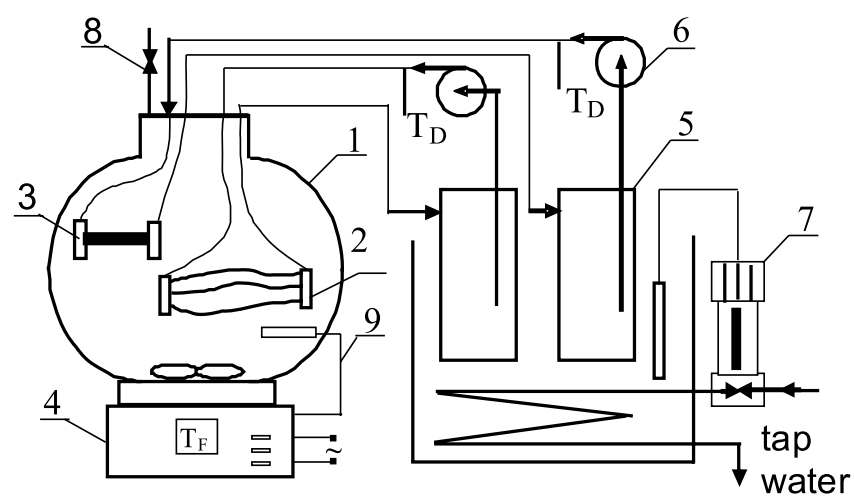

Figure 1. Experimental set-up. 1 - bioreactor (feed tank), 2 - MK2 module (membrane S6/2), 3 - MK1 module (membrane V8/2 HF), 4 - magnetic stirrer with heater, 5 - distillate tank, 6 - peristaltic pump, 7 - cooling water controller (valve AVTA, Danfoss), 8 - valve, 9 - temperature sensor (PT100). trol (thermometer PT 100). The temperature of the ethanol solutions was changed to the range $307-314 \mathrm{~K}$. The temperature of sucrose fermentation was 308-309 K. During all the experiments the distillate was supplied inside the membrane capillaries with the flow rate of $0.4 \mathrm{dm}^{3} / \mathrm{min}$ $(0.116 \mathrm{~m} / \mathrm{s}-\mathrm{S} 6 / 2$ and $0.216 \mathrm{~m} / \mathrm{s}-\mathrm{V} 8 / 2 \mathrm{HF})$. The inlet temperature of distillate was constant for all the experiments $(292 \pm 1 \mathrm{~K})$. The distillate tanks were placed in a water bath, which temperature was controlled by a thermostatic valve AVTA (Danfoss, Denmark) fed with the tap water. The distillate temperatures were measured using thermometers with $\pm 0.2 \mathrm{~K}$ accuracy.

The application of a membrane distillation bioreactors for fermentation causes the ethanol concentration to be stabilized at a level of $30-40 \mathrm{~g} \mathrm{EtOH} / \mathrm{dm}^{3} \mathbf{1 4 , 1 5}$. For this reason the studies of ethanol separation were carried out using the standard solutions (ethanol + distilled water + $10 \mathrm{~g} \mathrm{NaCl} / \mathrm{dm}^{3}$ ) containing $0.3-40 \mathrm{~g} \mathrm{EtOH} / \mathrm{dm}^{3}$. The presence of alcohol may accelerate the wetting of hydrophobic membranes, and the salt dissolved in the feed can diffuse through the wetted pores into the distillate. Therefore, the investigations of $\mathrm{NaCl}$ content in the distillate made it possible to assess whether or not the used membranes became partly wetted during the module exploitation.

Apart from MD of the standard solutions of ethanol, long-term investigations of separation of the true broth were also conducted. A fermentation solution was prepared by dissolution of $100 \mathrm{~g}$ of sucrose in tap water, boiled three times. Commercially available Gamma Hefe yeast (Saccharomyces cerevisiae, AB Enzymes, Germany) was used as the microorganism in the amount of $5 \mathrm{~g} / \mathrm{dm}^{3}$. The fermentation process was carried out for 5 days in a continuous mode. After each series of experiments the installation was rinsed several times with deionised water (Simplicity 185, MILLIPORE, USA). The content of sugar and alcohol in the solution was determined on the basis of an analysis of the total organic carbon (TOC-Analyzer multi $\mathrm{N} / \mathrm{C}$, Analytic Jena). Ion chromatography was used to analyse the content of organic acids in the feed and distillate. The method of running the fermentation and analyses of solution concentrations was described in detail in previous papers $^{18}$.

After the fermentation experiments were completed the membranes were rinsed several times with distilled water and dried at ambient temperature. Subsequently, the air permeability measurements of Accurel PP membranes used in the study were performed. The permeability investigations were carried out at room temperature (298-300 K). The air from a gas cylinder permeated through the membrane from the tube side to the shell side. The flow rate of the air was measured using a mass flow meter Brooks 4800 Series (Brooks Instrument, USA), in the range of 10-100 $\mathrm{cm}^{3} / \mathrm{min}( \pm 1 \%)$. The pressure (the hydraulic resistance for a given air volume flow) was measured using an electronic manometer Druck DPI 104 (General Electric, USA) with accuracy $0.05 \%$.

The anion and cation concentrations were measured using an ion chromatography method with conductivity detector (850 Professional IC, Herisau Metrohm -Switherland). The separation of anions was performed on $1.7 \times 3.5 \mathrm{~mm}$ Metrosep $\mathrm{RP}$ guard column in series with a $250 \times 4.0 \mathrm{~mm}$ Metrohm A Supp5-250 analytical column. For cations separation a 150x4.0 mm Metrosep C2-150 analytical column was used. 
The electrical conductivity of examined solutions was measured by a 6P Ultrameter (Myron L Company).

\section{RESULTS}

The conducted studies confirmed that a volume of obtained MD distillate decreases along with an increase in the membrane thickness. The permeate flux was more than three times larger for membranes $\mathrm{S} 6 / 2$, which are three times thinner than the membranes V8/2 HF (Fig. 2). The driving force for the mass transfer in MD is expressed by the vapour pressure difference across the membrane $(\Delta p)$, caused by the existing temperatures and the compositions of the layers adjacent to the membrane ${ }^{14}$. Although an increase in the membrane thickness reduces heat loss due to thermal conductivity (which causes the enhancement of $\Delta \mathrm{p}$ value), the resistance of vapour diffusion through a membrane increases to a larger degree. As a result, the permeate flux is smaller for thicker membranes ${ }^{\mathbf{1 9}}$.

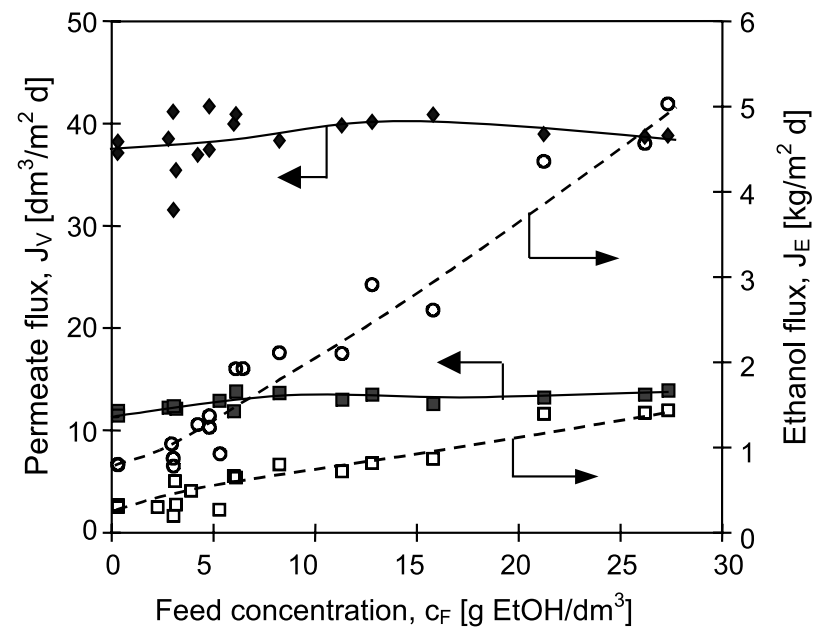

Figure 2. Influence of ethanol concentration in the feed on the permeate and ethanol flux. Membrane Accurel PP V8/2 HF: (匹) - permeate flux, (ם) - ethanol flux. Membrane Accurel PP S6/2: (•) - permeate flux, (O) - ethanol flux. Feed temperature 312$313 \mathrm{~K}$, distillate temperature $293 \mathrm{~K}$

In MD, all the volatile components of the feed are transferred through a non-wetted membrane to the distillate whose concentration depends on both the volatility of these components and the feed concentration. The influence in the ethanol concentration in the feed on its flux was also presented in Fig. 2. An increase of ethanol concentration from 2 to $27 \mathrm{~g} / \mathrm{dm}^{3}$ caused the ethanol flux to increase from 0.5 to $1.5 \mathrm{~kg} \mathrm{EtOH} / \mathrm{m}^{2} \mathrm{~d}$ and from 1 to $5 \mathrm{~kg} \mathrm{EtOH} / \mathrm{m}^{2} \mathrm{~d}$ for membranes V8/2 HF and S6/2, respectively.

The fermentation process for some species of yeast is conducted at temperatures lower than $313 \mathrm{~K}$. Considerably smaller differences in the magnitude of ethanol flux were obtained after lowering the feed temperature from 313 to $307 \mathrm{~K}$ (Fig. 3). In this case, the ethanol flux amounted to $1.4 \mathrm{~kg} \mathrm{EtOH} / \mathrm{m}^{2} \mathrm{~d}$ and $2.2 \mathrm{~kg} \mathrm{EtOH} / \mathrm{m}^{2} \mathrm{~d}$ for the membranes $\mathrm{V} 8 / 2 \mathrm{HF}$ and $\mathrm{S} 6 / 2$, at the highest feed concentration used in this study. A comparison of the values presented in Figs. 2 and 3 indicates that for a lower feed temperature $(307 \mathrm{~K})$ the differences in the efficiency of MD process for membranes V8/2 HF and S6/2 were smaller. This is due to the influence of the feed temperature on the magnitude of thermal polarization and due to the exponential character of vapour pressure dependence. Thinner membranes S6/2 were characterized with smaller diffusion and thermal resistances, and as a result the temperature polarisation for these membranes was higher, as was the observed influence of the feed temperature on the efficiency of the MD process.

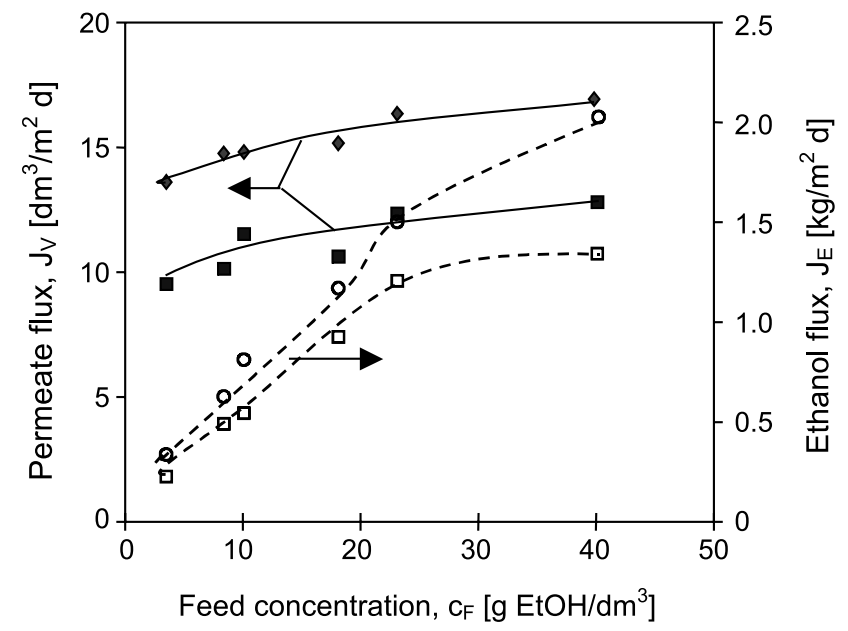

Figure 3. Influences of ethanol concentration in the feed on magnitude of permeate and ethanol flux. Membrane Accurel PP V8/2 HF: (ロ) - permeate flux, (ם) - ethanol flux. Membrane Accurel PP S6/ 2: (๑) - permeate flux, (०) - ethanol flux. Feed temperature $307 \mathrm{~K}$, distillate temperature $293 \mathrm{~K}$

In the case of ethanol production in the membrane distillation bioreactor the concentration of obtained distillate (the enrichment coefficient) is a more important parameter than the magnitude of permeate flux. The higher the enrichment coefficient, the lower the costs associated with further concentration of the alcohol solution. The obtained values of the enrichment coefficient were similar to the investigated membranes (S6/2 and V8/2 HF) and they depended to a large degree on the concentration and temperature of the feed (Figs. 4 and 5). At a low content of alcohol in the solution $\left(2-5 \mathrm{~g} \mathrm{EtOH} / \mathrm{dm}^{3}\right)$ the enrichment coefficient amounted to about 7 and it decreased to 3 when the feed concentration increased to $40 \mathrm{~g} \mathrm{EtOH} / \mathrm{dm}^{3}$. A decrease of temperature from 313 to $308 \mathrm{~K}$ slightly decreased the enrichment coefficient value. However, the opposite result was obtained for the ethanol concentration below $5 \mathrm{~g} \mathrm{EtOH} /$ $\mathrm{dm}^{3}$ (Fig. 5). That was probably due to the fact that the amount of ethanol transported through a membrane increases along with the temperature increase, which hinders the maintenance of a constant concentration at the feed/ membrane interfacial with regard to its low concentration.

The results of MD of the fermenting broth were markedly different from the separation of standard solutions of ethanol. During the experiments, the ethanol concentration in the broth varied in the range $22-44 \mathrm{~g} \mathrm{EtOH} / \mathrm{dm}^{3}$. The obtained enrichment coefficient amounted to $10-15$, thus it was considerably higher than that obtained for the standard solutions of ethanol (Fig. 6). In the previous study it was found that bubbles of $\mathrm{CO}_{2}$ formed during the fermentation had a significant influence on the result ${ }^{14}$. The bubbles cause a layer adjacent to the membrane to become enriched in alcohol, which affects the separation result during MD process.

Other volatile compounds are separated in the MD process in addition to ethanol, decreasing their concentration in 


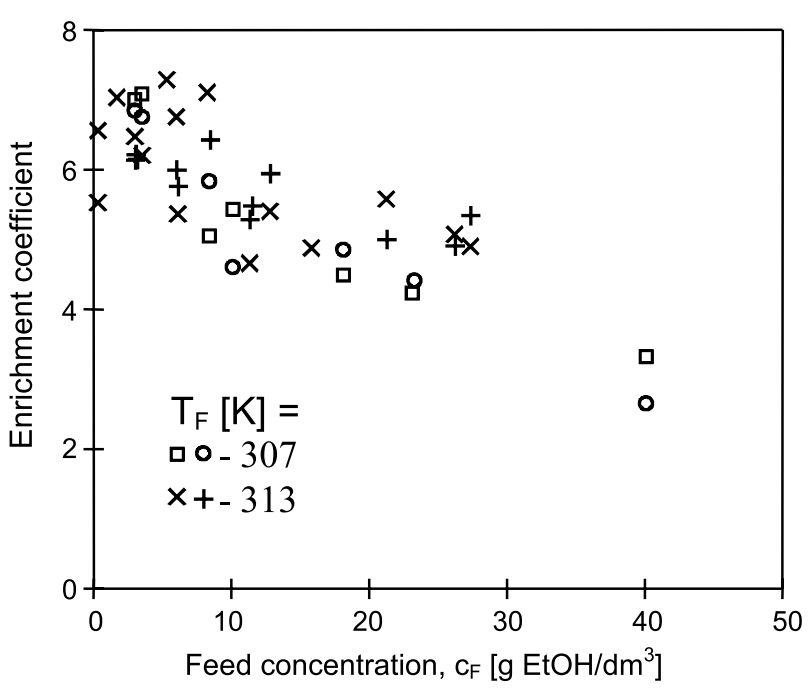

Figure 4. Influence of ethanol concentration in the feed on the value of enrichment coefficient. Membranes Accurel PP: (口), (+) - S6/2; (o), (x) - V8/2 HF

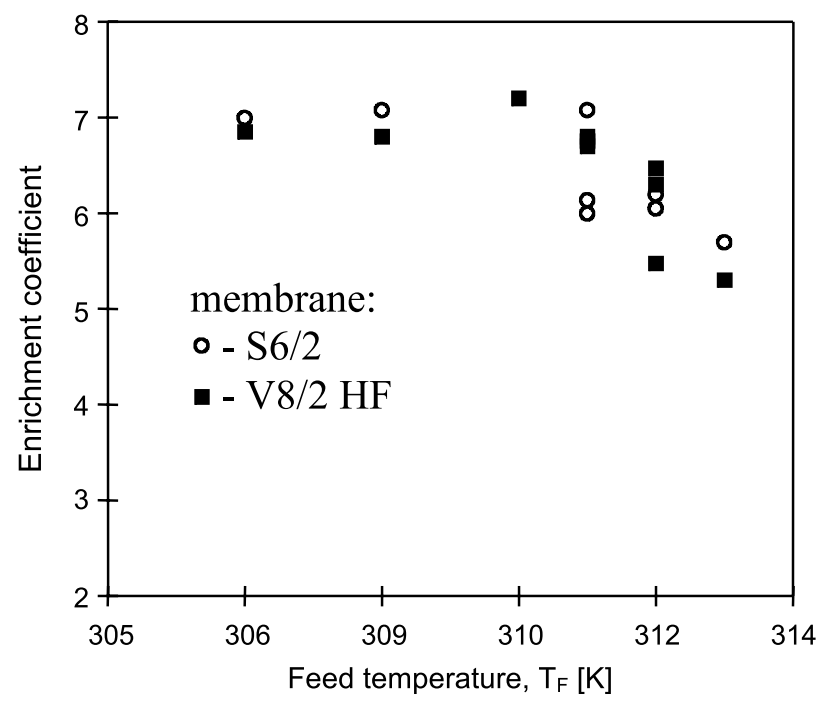

Figure 5. Influence of feed temperature on the enrichment coefficient for MD process of diluted ethanol solution. Feed concentration 3-4 g EtOH $/ \mathrm{dm}^{3}$

the broth. After 5 days of sucrose fermentation the solution contained formic, acetic, propionic, butyric, valeric and tartaric acids apart from ethanol. The amount of these components changed systematically, which additionally increased their content in the distillate (Fig. 7). The majority of the compounds detected in the broth was characterized by high boiling points, thus the distillate contained volatile acetate. The acetic acid is a strong inhibitor of fermentation, hence, its separation by MD increases the effectiveness of a bioreactor operation ${ }^{12}$.

The composition of fermentation solution may have a negative influence on hydrophobic membranes. However, the conducted long-term investigations demonstrated the high durability of used polypropylene membranes on the conditions existing in a bioreactor. The studies of fermentation integrated with MD were carried out for $400 \mathrm{~h}$, and no significant decrease in the MD module efficiency was observed (Fig. 6). The determination of salt content in the distillate by an IC method demonstrated over $99.9 \%$ salt rejection coefficient in the MD process. This result indi-

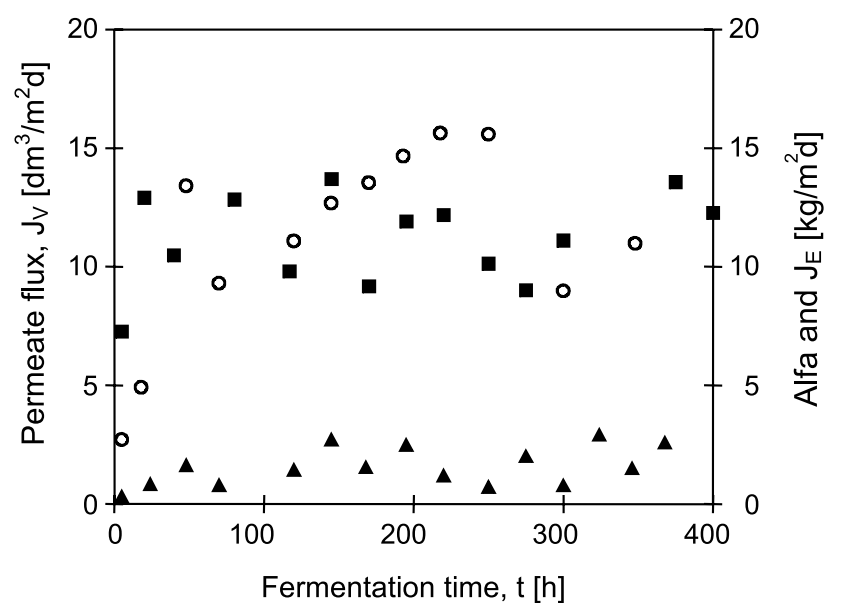

Figure 7. Changes of the value of permeate ( $\mathbf{})$ and ethanol (₫) flux and enrichment coefficient (Alfa) (o) during long-term fermentation conducted in membrane distillation bioreactor. Membrane Accurel PP S6/2

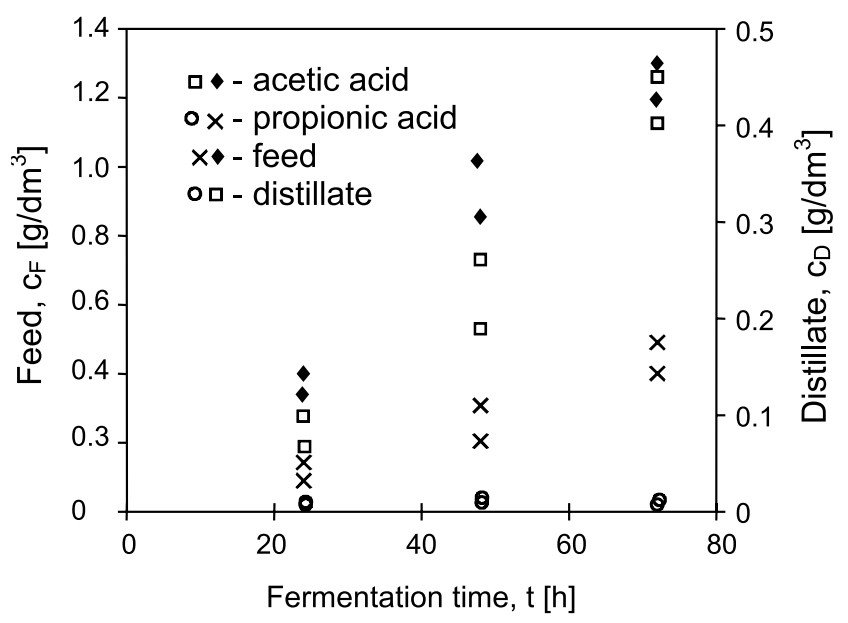

Figure 6. Changes of the concentration of acetic and propionic acids in broth and MD distillate depending on time of batch fermentation

cates that the used membranes did not become wetted by the solutions used in these studies.

The long-term fermentation investigations were conducted in the batch fermentation system. It was found that the degree of fermentation intensity affected the observed discrepancies in the obtained values of the enrichment coefficient and ethanol flux (Fig. 6). The tests of air permeability performed after completing fermentation demonstrated that the membranes taken out of the bioreactor after $400 \mathrm{~h}$ of fermentation had the value of air permeability by about $7 \%$ lower in comparison to those for new membranes. This result confirms previous observations that fermentation solutions cause only a slight biofouling in MD process $^{14}$.

\section{CONCLUSIONS}

MD can be successfully used for the separation of volatile compounds formed during sugar fermentation. Apart from ethanol, mainly acetic acid was evaporated from the feed into the distillate.

It was found that the membrane thickness did not have a significant influence on the value of the enrichment coefficient. Its value decreased along with an increase of alcohol concentration in the feed, and for the feed concentra- 
tion in the range from 0.5 to $40 \mathrm{~g} \mathrm{EtOH} / \mathrm{dm}^{3}$ the values of enrichment coefficient decreased from 7 to 3 . For true fermentation solutions, the value of enrichment coefficient was higher and varied in the range 10-15. In this case, the enrichment effect depended to a large degree on the intensity of fermentation and on the amount of evolved $\mathrm{CO}_{2}$ bubbles.

The polypropylene membranes used in the study were not wetted by the solutions of ethanol and the broth. This indicates that Accurel PP capillary membranes can be successfully used for the separation of ethanol produced in the membrane distillation bioreactor.

\section{ACKNOWLEDGEMENTS.}

The Polish State Committee for Scientific Research supported this work (2009-2012).

\section{LITERATURE CITED}

1. Ponton, J.W. (2009). Biofuels: Thermodynamic sense and nonsense, J. Cleaner Prod., 17, 896-899. DOI:10.1016/ j.jclepro.2009.02.003.

2. Demirbas, A. (2007). Progress and recent trends in biofuels, Prog. Energy Combust. Sci., 33, 1-18. DOI:10.1016/ j.pecs.2006.06.001.

3. Grajek, W., Gumienna, M., Lasik, M. \& Czarnecki, Z. (2008). Perspectives for ethanol production from starchy matherials, Przem. Chem., 87 (11), 1094-1101 (in Polish).

4. Sassner, P., Galbe, M. \& Zacchi, G. (2008). Technoeconomic evaluation of bioethanol production from three different lignocellulosic materials, Biomass Bioenergy, 32, 422430. DOI:10.1016/j.biombioe.2007.10.014.

5. Bai, F.W., Anderson, W.A. \& Moo-Young, M. (2008). Ethanol fermentation technologies from sugar and starch feedstocks, Biotechnol. Adv., 26, 89-105. DOI:10.1016/ j.biotechadv.2007.09.002.

6. Morin-Couallier, E., Payot, L.T., Pastore Bertin, A. \& Lameloise, M.L. (2006). Recycling of distillery effluents in alcoholic fermentation, Appl. Biochem. Biotechnol., 133, 217238. DOI: $10.1385 / \mathrm{ABAB}: 133: 3: 217$.

7. Morin-Couallier, E., Salgado-Ruiz, B., Lameloise, M.L. \& Decloux, M. (2006). Usefulness of reverse osmosis in the treatment of condensates arising from the concentration of distillery vinasses, Desalination, 196, 306-317. DOI:10.1016/ j.desal.2006.02.002.

8. Takaya, M., Matsumoto, N. \& Yanase, H. (2002). Characterization of membrane bioreactor for dry wine production, J. Biosci. Bioeng., 93 (2), 240-244. DOI:10.1016/S13891723(02)80021-4.

9. Park, B.G., Lee, W.G., Chang, Y.K. \& Chang, H.N. (1999). Long-term operation of continuous high cell density culture of Saccharomyces cerevisiae with membrane filtration and on-line cell concentration monitoring, Bioprocess Eng., 21, 97-100. DOI: 10.1007/PL00009070.

10. Maiorella, B.L., Blanch, H. W. \& Wilke, C.R. (1984). Economic evaluation of alternative ethanol fermentation processes, Biotechnol. Bioeng., 26, 1003-1025. DOI: 10.1002/ bit.260260902

11. Gyamerah, M. \& Glover, J. (1996). Production of ethanol by continuous fermentation and liquid - liquid extraction, J. Chem. Tech. Biotechnol., 66, 145-152. DOI: 10.1002/ (SICI)1097-4660(199606).

12. Nakao, S., Saitoh, F., Asakura, T., Toda, K. \& Kimura, S. (1987). Continuous ethanol extraction by pervaporation from a membrane bioreactor. J. Membr. Sci., 30, 273-287. DOI:10.1016/S0376-7388(00)80123-4.
13. Miyazawa, K.I. \& Kokugan, T. (1998). Effect of production removal by pervaporation on ethanol fermentation, J. Ferment. Bioeng., 86(5). 488-493. DOI:10.1016/S0922338X(98)80157-8.

14. Gryta, M. (2001). The fermentation process integrated with membrane distillation, Separ. Purif. Technol., 24, 283-296. DOI:10.1016/S1383-5866(01)00132-0.

15. Gryta, M., Morawski, A.W. \& Tomaszewska, M. (2000). Ethanol production in membrane distillation bioreactor, Catal. Today, 56, 159-165. DOI:10.1016/S0920-5861(99)00272-2.

16. Gryta, M. \& Barancewicz, M. (2010). Influence of morphology of PVDF capillary membranes on the performance of direct contact membrane distillation, J. Membr. Sci., 358, 158-167. DOI:10.1016/j.memsci.2010.04.044.

17. Taylor, R. \& Krishna, R. (1993). Multicomponent mass transfer, New York, USA, John Willey.

18. Barancewicz, M., Sasim, M. \& Gryta, M. (2009). Zastosowanie chromatografii jonowej do badania przebiegu fermentacji, Prace $i$ Studia, 77, 89-101.

19. El-Bourawi, M.S., Ding, Z., Ma, R., \& Khayet, M. (2006). A framework for better understanding membrane distillation separation process, J. Membr. Sci., 285, 4-29. DOI: 10.1016/ j.memsci.2006.08.002. 